\title{
Performance of Precast Beam to Column Connection With Billet Connector Using FEM
}

\author{
Ashraf Adel Almohagry ${ }^{1 *}$, Zainah Ibrahim ${ }^{1}$, Farooq Ahmed Athar ${ }^{1}$, Muhammad Usman \\ Hanif $^{2}$, Ahmad Zaki ${ }^{3}$ \\ ${ }^{1}$ Department of Civil Engineering Faculty of Engineering, University of Malaya, Kuala Lumpur, Malaysia \\ ${ }^{2}$ School of Civil and Environmental Engineering, National University of Sciences and Technology, Islamabad, Pakistan \\ ${ }^{3}$ Department of Civil Engineering Faculty of Engineering, Universitas Muhammadiyah Yogyakarta, Yogyakarta, Indonesia \\ *Corresponding author. Email: ahmad.zaki@umy.ac.id
}

\begin{abstract}
In precast concrete structures, connections play an important role in ensuring the safety of the structure. Current design practice in structural analysis assumes the connection as pinned or rigid. However, this cannot be relied upon for safety against collapse because during service the actual connection may react differently by rotating and, consequently, deviating from the desired response for what it was designed for. This paper investigates the performance of a precast beam-to-column connection with billet connector using three-dimensional non-linear finite element model in Finite Element Analysis (FEA) software, Abaqus. The material properties of concrete were defined using a non-linear concrete damage plasticity model (CDPM). This model was used to predict the connection behavior under monotonic and cyclic loading when different parameters were set such as dilation angle, interaction properties and friction factor. Furthermore, the moment resistance and failure mechanism of the connection were investigated. The fixity factor was calculated, and the connection was classified using the 'beam line' method through investigating the moment-rotation $(\mathrm{M}-\phi)$ and the response of the beam. The FE analysis was also validated against experimental results. This process was carried out to obtain the most efficient method of designing a precast connection in terms of maximum displacement, stress generated, strength, hysteretic behaviour, and stiffness degradation.
\end{abstract}

Keywords-Finite Element Analysis, Precast Concrete, Beam to Column Connection, CDPM

\section{INTRODUCTION}

Simulation and its implementation in civil engineering has grown to become an important factor in contribution to the industry as it provides an approximate prediction on the response of a given structure under desired loading. However, the validation of the finite element model is equally important as the simulation itself as there has to exist an agreement between the simulation and the experiment for its effectiveness. Furthermore, it is very important to understand that FEM can only provide an estimated result of the problem [1]. The implementation of Industrialized Building systems (IBS) in Malaysia is becoming more popular within the construction industry. The usage of this system is preferred over the traditional methods of construction as it reduces the wastage of materials and the time for project completion. Besides, IBS reduces the environmental impacts when compared to conventional construction methods. In Malaysia, IBS is implemented using precast concrete. Precast concrete components are fabricated in the factory and then brought to the site to for assembling. Precast concrete components need to be joined together to form a complete structure as it is a definite element on its own [2]. The assembly is done using connections. These connections connect the precast components together and transfer forces between the elements of a precast structure. Hence, connections are a vital part of the precast concrete system and have important contribution in deciding the type of precast frame and its limitations as well as the erection methods used during construction [3]. Since connections show different behaviour under different loadings and conditions, it is best to formulate the problem in a numerical approach using Finite Element software. This will help in stimulating and understanding the flexural behaviour of the connection [4]. Therefore, this study presents a numerical approach to stimulating and understanding the behaviour of billet connector in precast beam to column connection.

\section{LITERATURE REVIEW}

\subsection{Precast Connections}

When compared to the traditional methods, precast concrete has many advantages over in-situ concrete such as less wastage and more energy efficiency, better quality, healthier 
and safer working environment, as well as efficient and economical. The definition of a connection is the action of forces (e.g. tension, shear, compression) or moments (bending, torsion) through an assembly comprising one or more interfaces. Hence, the design of the connection is a function of both the structural elements and the joints between them [3]. In a precast structure especially in skeletal frames, beam-to-column connections are the most vital elements. In the frame precast structure, the beam-to-column connection is categorized in relation to the definition of moment rotation characteristics into three main categories. Those categories are rigid, semi-rigid and pinned connections as shown in Fig. 1 [3].

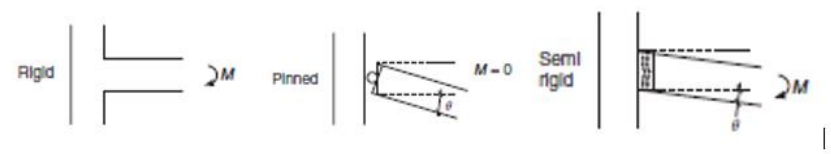

Fig. 1. Three main categories of beam to column connection in precast frame structures [3]

\subsection{Load Displacement relationship}

The load displacement relationship helps in determining the level of ductility of the connection. The ratio of failure displacements to yield displacements are used to express the displacement ductility factor [5]. Typically, a connection needs to be ductile to avoid sudden failure because a brittle connection would cause the structure to fail instantly and cause huge safety issues. The connection needs to allow for plastic deformations under loading without compromising the safety of the structure through any extensive reduction in its ability to resist forces. This relationship is illustrated in Fig.2.

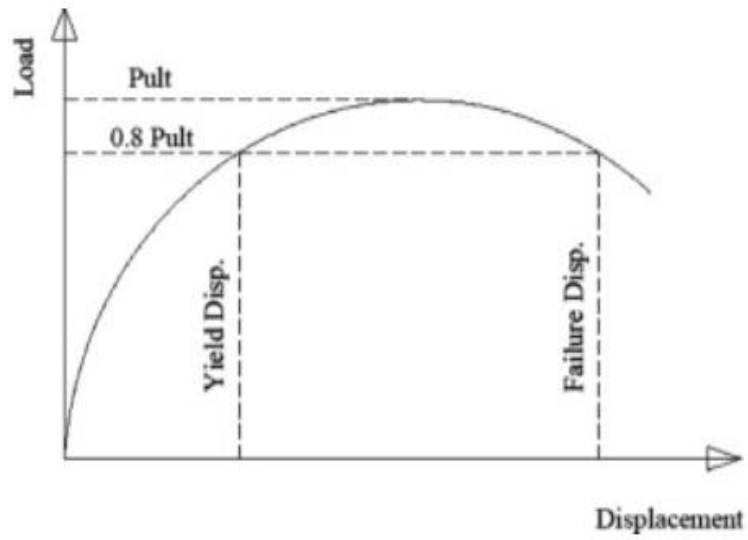

Fig. 2. Failure and yield displacement definition [5]

\subsection{Moment Rotation (M- $\phi$ ) relationship}

To understand the connection type and how it transmits energy between the beam and the column, an accurate understanding of the connection behaviour needs to be developed. To do that, the moment rotation curve of the connection is analyzed [6]. In other words, understanding the behaviour of the connection will allow to identify the rigidity of the connection and hence will allow for understanding the amount of energy that can be transferred through the connection. For instance, rigid connections can transmit full moment unlike the pinned connections which transfer no moment [7].

\subsection{Connection Classification}

The connection classification method is based on a system developed by Ferreira [8] in which the connection is classified based on its fixity factor. The system is used to classify the connection into three categories which are rigid, semi-rigid and pinned based on the zones they fall within as shown in Table I and Fig. 3.

Table I. Connection classification based on fixity factor [8]

\begin{tabular}{|c|c|c|}
\hline Zone & Fixity factor $(\gamma)$ & Connection Classification \\
\hline 1 & $\gamma \leq 0.14$ & Pinned connection \\
\hline 2 & $0.14<\gamma \leq 0.40$ & $\begin{array}{c}\text { Semi rigid connection with } \\
\text { low strength }\end{array}$ \\
\hline 3 & $0.40<\gamma \leq 0.67$ & $\begin{array}{c}\text { Semi rigid connection with } \\
\text { medium strength }\end{array}$ \\
\hline 4 & $0.67<\gamma \leq 0.90$ & $\begin{array}{c}\text { Semi rigid connection with } \\
\text { high strength }\end{array}$ \\
\hline 5 & $\gamma>0.90$ & Rigid connection \\
\hline
\end{tabular}

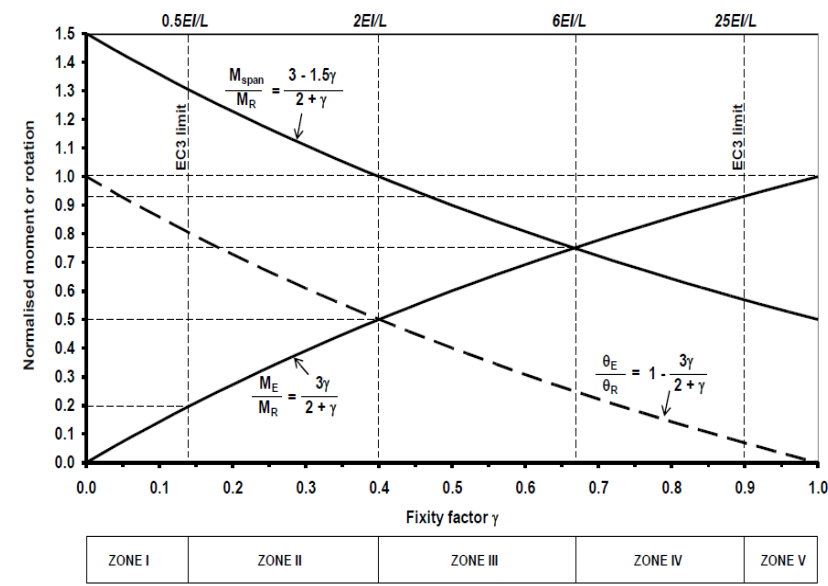

Fig. 3. Classification system for pinned, semi-rigid, fully rigid beam-tocolumn connections [9]

\subsection{Finite Element Analysis}

Numerical models can provide a clear formulation and efficient simulation that reflects to the actual features of the real structure. Hence, numerical models can produce accurate results when compared to the actual structure [10]. The vital element for describing a physical system in a particular phenomenon using mathematical models is a quantity known as the "State Variable" [11]. The state of variables is essential for analytically examining the process. These variables are determined by a series of mathematical equations which are also known by "Mathematical Model of a Process" [11]. Generally, the mathematical models are correlated with differential equations. For instance, in a mathematical model, a differential equation is thoroughly satisfied by one or more dependent variables, satisfying the particular settings on the 
boundary in a physical domain of interest of independent variables, is called the "Boundary Value Problem". The boundary value problems are solved through a computational technique called "Finite Element Method" (FEM) which is also known by "Finite Element Analysis" (FEA), that attains a converging solutions to these type of problems [12].

\section{METHODOLOGY}

\subsection{Material Properties}

For the sake of this study, the compressive strength of the concrete was taken as $40 \mathrm{MPa}$ and its mechanical properties are shown in Table II. Density $(\gamma)$, Young's modulus, and Poisson's ratio selected were $2400 \mathrm{~kg} / \mathrm{m}^{3}, 27.8975 \mathrm{GPa}$ and 0.15 , respectively. Furthermore, dilation angle, eccentricity, ratio of biaxial compressive strength to uniaxial compressive strength $\left(\mathrm{fb}_{0} / \mathrm{fc}_{0}\right)$, ratio of second stress invariant on tension strain $(\mathrm{k})$ and viscosity parameter were taken as $56^{\circ}, 0.1,1.16$, 0.667 and 0.01 respectively.

Table II. Mechanical properties of concrete grade 40 MPA

\begin{tabular}{|c|c|c|c|}
\hline $\begin{array}{c}\text { Characteristic } \\
\text { compressive } \\
\text { strength }(\boldsymbol{\sigma c u}), \\
\text { MPa }\end{array}$ & $\begin{array}{c}\text { Density, } \\
\mathbf{T} / \mathbf{m 3}\end{array}$ & $\begin{array}{c}\text { Elastic } \\
\text { modulus }(\boldsymbol{E}), \\
\mathbf{M P a}\end{array}$ & $\begin{array}{c}\text { Poisson's } \\
\text { ratio (v) }\end{array}$ \\
\hline 40 & 2.4 & 27897.52366 & 0.15 \\
\hline
\end{tabular}

In this study, CDPM was used. Material properties of the concrete were defined based on data obtained from previous researchers. CDPM values that were used are listed in Table III. The parameters, excluding the dilation angle, were defined based on a study made by previous researcher CDPM developed by [13]. In this study, the value of the dilation angle used was $56^{\circ}$ instead of the original value, which was $35^{\circ}$, as it was found to best fit this model to validate the data.

Table III. Concrete Damage Plasticity (CDP) parameters

\begin{tabular}{|c|c|c|c|c|}
\hline $\begin{array}{c}\text { Dilation } \\
\text { angle }\end{array}$ & Eccentricity & $\mathbf{K}$ & fbo/fco & $\begin{array}{c}\text { Viscosity } \\
\text { parameter }\end{array}$ \\
\hline 56 & 0.1 & 0.667 & 1.16 & 0.01 \\
\hline
\end{tabular}

Regarding the steel, the density $(\gamma)$, Elasticity of steel $(E s)$, and Poisson's ratio $(v)$ selected were $7850 \mathrm{~kg} / \mathrm{m}^{3}, 210 \mathrm{GPa}$ and 0.3 , respectively. The yield strength $\left(f_{y}\right)$ of the steel was taken as $440 \mathrm{MPa}$. In order to account for non-linearity in material, the variation of stress against strain in steel was inputted using true stress and true strain formulae.

\subsection{Simulation}

The load was applied with an increment of $5 \mathrm{kN}$ at a distance of $3 \mathrm{~d}$ of the beam from the column face (where $d$ is the beam effective depth). The parameters of the modified Coulombic friction model used in this study follows the values proposed by Nguyen et al. [14]. Further details of the modelling and simulation can be found in [15].

\subsection{Moment Rotation Method}

The value of rotation $(\phi E)$ that was used in this study was obtained from a study made by Gorgun [16]. The vertical deflection of the beam was used to calculate the rotation. The vertical deflection was measured at the face of the beam in reference to the column. Moreover, this method was also used by other researchers like Ferrier and Mahdi [17-18]. The equation to calculate the rotation is shown in Eq. 1.

$$
\begin{aligned}
& \text { Connection rotation }(\phi) \\
& =\phi \text { column }-\phi \text { beam }
\end{aligned}
$$

Where, $\phi$ column $=$ column rotation bbeam $=$ beam rotation

The connection classification was based on Monforton's fixity factor $(\gamma)$. The fixity factor was calculated, and the results were used to classify the connection in terms of the rigidity according to the zones it falls within.

\section{RESULTS AND DISCUSSION}

\subsection{Load - Displacement Relationship}

The load deflection response of the system under monotonic loading was taken at LVDT8. The FE model aligns with the experimental results of BIC 2 . The crack formulation was seen around $21.93 \mathrm{kN}$ in the FE modelling while it formed at 19.49 $\mathrm{kN}$ in the experimental. The slight difference in results might be due several factors in the experimental work such as human error or mishandling the specimen during casting and transportation while the FE model had a perfect geometry. As seen from Fig. 4, the FE model results showed that the model was a little stiffer than the experimental. Moreover, the FE model fails at $78 \mathrm{kN}$ while the experimental fails at $70 \mathrm{kN}$. Hence, the results obtained shows that the model successfully illustrates a close approximation of the experimental results.

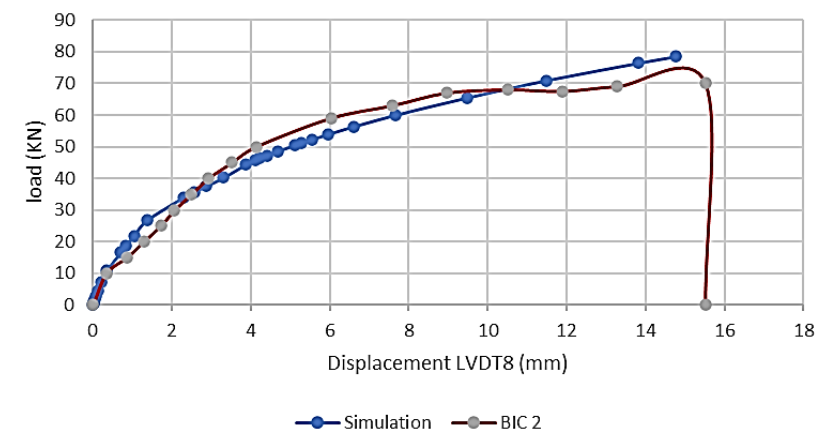

Fig. 4. Load deflection response under monotonic loading

\subsection{Moment Rotation (M- $\phi$ ) Relationship}

The moment rotation $(\mathrm{M}-\phi)$ relationship is plotted using the data obtained from the simulation and experimental as shown in Fig. 5 and Fig. 6. In addition, within the same graph the beam-line relationship for the model is plotted. The point of intersection between the moment-rotation and the beam-line method is indicated with the letter $\mathrm{E}$ as shown in Fig. 5. 


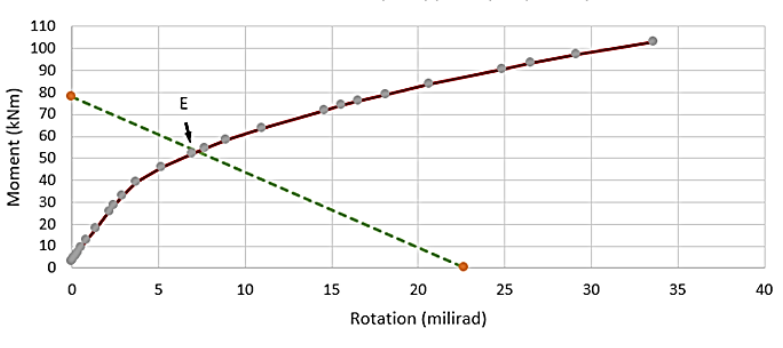

- - - Beam Line (Simulation) - - Moment-Rotation (Simulation)

Fig. 5. Moment-rotation (M- $\phi$ ) graph for BIC 2 (FEM)

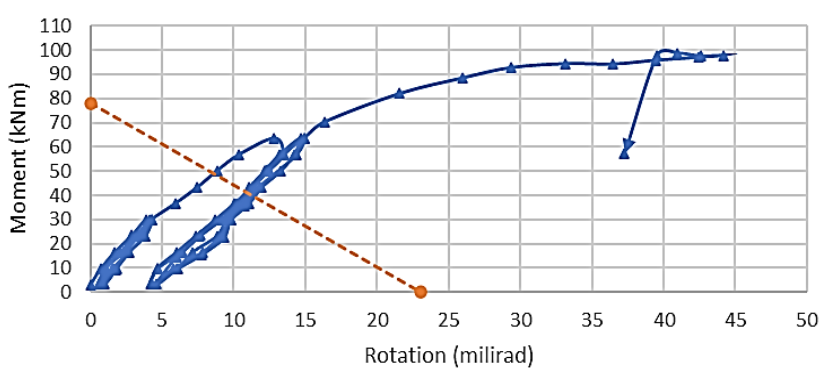

$\longrightarrow$ Moment-Rotation (Experimental) $\quad$--०-- Beam Line (Experimental)

Fig. 6. Moment-rotation (M- $\phi$ ) graph for BIC 2 (Experimental)

The point of intersection represents a Moment $\left(\mathrm{M}_{\mathrm{E}}\right)$ of 53.0 $\mathrm{kNm}$ and a rotation $\left(\phi_{E}\right)$ of $7.20 \mathrm{~m} . \mathrm{rad}$. Therefore, the Secant stiffness $\left(\mathrm{S}_{\mathrm{E}}\right)$ is calculated and found to be $7.36 \mathrm{kNm} / \mathrm{m}$.rad. On the other hand, the experimental results have values of $49.0 \mathrm{kNm}, 8.70 \mathrm{~m} . \mathrm{rad}$ and $5.63 \mathrm{kNm} / \mathrm{m} . \mathrm{rad}$ for the Moment $\left(\mathrm{M}_{\mathrm{E}}\right)$, rotation $\left(\phi_{E}\right)$ and Secant stiffness $\left(\mathrm{S}_{\mathrm{E}}\right)$ respectively.

\subsection{Failure mode and Crack Propagation (Damage T)}

It was observed that the failure occurred when the ultimate moment was reached, and the plastic hinge was formed at both the experimental specimen and the simulation model. The failure mode of both experiment and simulation are shown in Fig. 7 for comparison and the steel slippage is shown in Fig. 8. Furthermore, extensive joint cracking failure was observed at both the experimental and the simulation model which is represented by the cracks within the connection's zone.

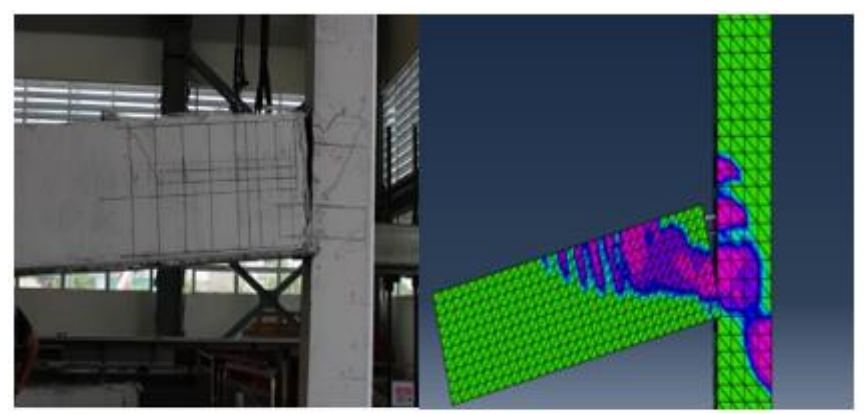

Fig. 7. Visual illustration of the failure mode (Experimental \& Simulation)

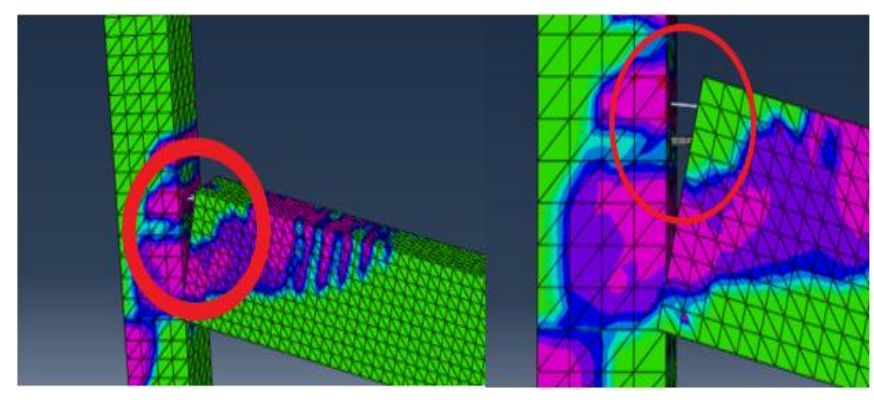

Fig. 8. Connection bolt and steel slippage (Simulation)

\subsection{Connection classification (Fixity factor)}

The results from the simulation and the calculated value of the fixity factor are shown in Table IV. Through referring to the classification system produced by Ferreira et al. [8], it can be concluded that the connection in the model falls in zone 3 as well. Hence, the model follows the same behaviour shown by the connection that was tested in the laboratory in terms of rigidity.

Table IV. Monforton's Fixity Factor (Results)

\begin{tabular}{|c|c|c|}
\hline Connection & Experiment & Simulation \\
\hline $\begin{array}{c}\text { Moment capacity } \\
(\mathrm{kNm})\end{array}$ & 94.57 & 102.98 \\
\hline $\begin{array}{c}\text { Connection rotation } \\
\left(\phi_{\mathrm{E}}\right)(\mathrm{milirad})\end{array}$ & 9.90 & 7.2 \\
\hline Secant stiffness $\left(\mathrm{S}_{\mathrm{E}}\right)$ & 9.55 & 7.36 \\
\hline $\begin{array}{c}\text { Intersection at beam } \\
\text { line kNm }(\mathrm{E})\end{array}$ & 44.4 & 53 \\
\hline Fixity Factor $(\gamma)$ & 0.469 & Zone III \\
\hline $\begin{array}{c}\text { Classification }(\text { Table } \\
\text { I) }\end{array}$ & Zone III & \\
\hline
\end{tabular}

\section{CONCLUSION}

The finite element model was developed and successfully validated against the experimental work. Doing so, can ease any future parametric studies carried out on the connection without the need to perform extensive laboratory work. This is because the validated model provides better method of investigation in terms of cost effectiveness and time efficiency.

Reducing the use of concrete in experimental work will reduce the harmful impact on the environment. Therefore, the usage of Finite Element Analysis reflects directly in the environment by decreasing the carbon footprint during casting of concrete. This is because FEM requires a smaller number of specimens to investigate the connection behaviour.

Extensive testing on the connection prior to using it for any project is necessary to ensure its functionality and level of safety. Hence, using FEM can increase the number of trial tests conducted on the connection. Hence, this helps in improving the safety of the connection under different loading conditions. This will allow for a safer system that will keep the public safe when residing or using any precast structure. 


\section{ACKNOWLEDGMENT}

The authors would like to thank Allah SWT for all His blessings that made the completion of this research possible and express their gratitude to all the people who showed support while conducting this study.

This study was also supported by the University Malaya Research Grant (Faculty Grant Project No. GPF015A-2018 and GPF004A-2019).

\section{REFERENCES}

[1] Srinivas, Kartik. (2020). Verifications and Validations in Finite Element Analysis (FEA).

[2] Sai, B. P. V. N., Agarapu, D. C. K., \& Eluru, A. (2020). Assay of moment resisting precast and monolithic frames using ABAQUS software. Materials Today: Proceedings. doi: 10.1016/j.matpr.2020.03.735

[3] Elliott, K. S. (2002). Precast concrete structures. Oxford: Butterworth-Heinemann.

[4] Le, T. D., Pham, T. M., \& Hao, H. (2020). Numerical study on the flexural performance of precast segmental concrete beams with unbonded internal steel tendons. Construction and Building Materials, 248, 118362. doi: 10.1016/j.conbuildmat.2020.118362

[5] Tawfik, A. S., Badr, M. R., \& Elzanaty, A. (2014). Behavior and ductility of high strength reinforced concrete frames. HBRC Journal, 10(2), 215-221. doi: 10.1016/j.hbrcj.2013.11.005

[6] Shabanian, S. M., Abdollahzadeh, G., \& Davoodi, M. (2019). Evaluation of the moment-rotation curve of steel beam-to-column joints with flange-plate. Asian Journal of Civil Engineering, 21(3), 517-531. doi: 10.1007/s42107-019-00213-2

[7] Bidin, W. N. W. (2017). Full scale testing of precast beam to column connection using billet connector and beam half joint subjected to reversible loading, Master's dissertation, University of Malaya, Kuala Lumpur, Malaysia.
[8] Ferreira, M., Elliott, K. S., de Aranjo, D., \& El Debs, M. K. (2005). Analysis of Multi-storey Precast Frames Considering Beam-Column Connection with Semirigid Behaviour, Keep Concrete Attractive, FIB Symposium, Budapest, May 23-25 2005,(pp. 496-501).Hungary

[9] Elliott, K. S., \& Jolly, C.K. (2013). Multi-Storey Precast Concrete Framed Structures, 2nd edition. John Wiley, London.

[10] Aslani, F., \& Jowkarmeimandi, R. (2012). Stress-strain model for concrete under cyclic loading. Magazine of Concrete Research, 64(8), 673-685. doi: 10.1680/macr.11.00120

[11] Koutromanos, I., McClure, J., \& Roy, C. J. (2018). Fundamentals of finite element analysis: linear finite element analysis. Hoboken, NJ: John Wiley \& Sons, Inc.

[12] Hutton, D. V. (2004). Fundamentals of finite element analysis. Boston: McGraw Hill.

[13] Carreira, D. J., \& Chu, K.-H. (1985). Stress-Strain Relationship for Plain Concrete in Compression. American Concrete Institute Journal Proceedings, 82(6), 797-804

[14] Nguyen, Quy \& Livaoğlu, Ramazan. (2019). Shear connectors on concrete-to-concrete interface surfaces: A numerical investigation on 3D frames, in the Proceeding of the 5th International Conference on Earthquake Engineering and Seismology (5 ICEES), 8-11 October 2019, Ankara, Turkey.

[15] Almohagry, A. A., (2020). Optimisation of precast beam to column connection with billet connector using FEM. University of Malaya, Kuala Lumpur, Malaysia.

[16] Gorgun, H. (1997). Semi-rigid Behaviour of Connections in Precast Concrete Structures. PhD. Thesis, University of Nottingham, United Kingdom.

[17] Ferreira, M. (1999). Deformability of Beam-Column Connection in Precast Concrete Structures. PhD. Thesis, University of Nottingham, United Kingdom.

[18] Mahdi, A. A. (1992). Moment Rotation Effects on Stability Columns in Precast Concrete Structures. PhD. Thesis, University of Nottingham, United Kingdom. 